\title{
Association of homocysteine with type 2 diabetes: a meta-analysis implementing Mendelian randomization approach
}

\author{
Tao Huang ${ }^{1,2,3}$, JingJing Ren ${ }^{4}$, Jinyan Huang ${ }^{5}$ and Duo Li $i^{2,3^{*}}$
}

\begin{abstract}
Background: We tested the hypothesis that elevated homocysteine (Hcy) level is causally associated with increased risk of type 2 diabetes mellitus (T2DM).

Results: The meta-analysis and Mendelian randomization analysis were performed among 4011 cases and 4303 controls. The absolute pooled mean Hcy concentration in subjects with MTHFR $677 T \mathrm{~T}$ was $5.55 \mu \mathrm{mol} / \mathrm{L}(95 \% \mathrm{Cl}$, 1.33 to 9.77) greater than that in subjects with MTHFR 677CC in T2DM. Overall, the T allele of the MTHFR 677 C > T conferred a greater risk for T2DM [Random effect (RE) $\left.O R=1.31(1.17-1.64), I^{2}=41.0 \%, p=0.055\right]$. The random effect (RE) pooled OR associated with T2DM for MTHFR 677TT relative to the 677CC was [RE OR $=1.38(1.18-1.62)]$. The fixed-effect pooled OR of the association for the MTHFR 677 TT vs CT was 1.29 (95\% Cl, 1.09-1.51). MTHFR 677 TT showed a significantly higher risk for T2DM compared with MTHFR 677 CC + CT [Fixed effect (FE) OR=1.32(1.14-1.54), $\left.\mathrm{I}^{2}=0.0 \%, \mathrm{p}=0.686\right]$. The absolute pooled mean Hcy concentration in individuals with T2DM was $0.94 \mu \mathrm{mol} / \mathrm{L}(95 \% \mathrm{Cl}$, $0.40-1.48)$ greater than that in control subjects. The estimated causal OR associated with T2DM was 1.29 for $5 \mu \mathrm{mol} / \mathrm{L}$ increment in Hcy.
\end{abstract}

Conclusions: Our findings provided strong evidence on the causal association of Hcy level with the development of T2DM.

Keywords: Homocysteine, MTHFR, Type 2 diabetes

\section{Background}

The pathophysiology of type 2 diabetes mellitus (T2DM) characterized by a high incidence of vascular complications is complex and multifactorial [1]. The major cause of T2DM and its complications has not yet been clarified. In recent years, plasma homocysteine (Hcy) level, a sulphur-containing non-protein amino acid in the metabolism of methionine, has been reported to be associated with the vascular complications of diabetes [2]. In patients with diabetes, elevated Hcy levels were associated with insulin resistance [3] and nephropathy [4]. Of note, several studies have demonstrated that elevated Hcy levels predict the risk of death or coronary events in patients with T2DM [5,6]. However, conflicting results

\footnotetext{
* Correspondence: duoli@zju.edu.cn

${ }^{2}$ Department of Food Science and Nutrition, Zhejiang University, 268 Kaixuan Road, Hangzhou 310029, China

${ }^{3}$ APCNS Centre of Nutrition and Food Safety, Hangzhou, China

Full list of author information is available at the end of the article
}

regarding the Hcy level in patients with diabetes have been reported. Some studies found that plasma Hcy levels were increased $[7,8]$, unchanged [9-11], or decreased $[12,13]$ in patients with T2DM.

The candidate gene approach is widely used for identifying genes involved in complex human diseases [14]. 5,10 methylene-tetrahydrofolate reductase (MTHFR) is the key rate-limiting enzyme required for the conversion of dietary folate to 5-methyltetrahydrofolate, the methyl group donor required for the remethylation of Hcy to methionine in vivo [15]. Hyperhomocysteinemia (HHcy) may be due to the presence of a thermolabile isoform of this key enzyme. A single base pair $(677 \mathrm{C}>\mathrm{T})$ substitution in the human MTHFR gene predicts phenotypic expression of a heat-sensitive variant with reduced enzymatic activity [16]. Elevated Hcy level caused by MTHFR genetic variants has been demonstrated to be associated with insulin resistance [17-19]. Hcy exerts detrimental effects on a number of cell lineages including endothelial cells and

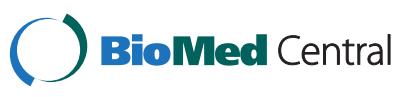


neuronal cells through production of reactive oxygen species (ROS) [20]. Both acute and prolonged exposure to Hcy had detrimental effects on beta cell glucose metabolism, insulin secretory responsiveness and cell viability $[20,21]$. Hcy generates ROS in a redox-cycling reaction that explains the decline in viability of insulin-secreting cells, leading to reduced glucokinase phosphorylating ability, diminished insulin secretory responsiveness and cell death [22]. Based on its biological functions, this variant has been considered an ideal candidate for genetic polymorphism for predisposition to diabetes [23], as it is common in many populations studied to date and the genotype correlates highly with the plasma Hcy level in a dose-dependent fashion [24].

In recent years, there have been a number of casecontrol studies investigating the association between the $677 \mathrm{C}>\mathrm{T}$ polymorphism in the MTHFR gene and T2DM or diabetes-related complications [12,16,25-40]. However, these studies have reported conflicting results, which has prevented a definitive conclusion to date. The associations of Hcy, MTHFR polymorphism and T2DM are still inconclusive.

To provide an answer to these contradictory results and elucidate the possible mechanism, a meta-analysis of the published literature regarding the risk for T2DM associated with an elevated Hcy level and the MTHFR $677 \mathrm{C}>\mathrm{T}$ was conducted. In this meta-analysis, the estimate of the genetic association of each individual study and a pooled estimate of this association were obtained. Furthermore, to test the hypothesis that elevated Hcy is causally related to increased risk of T2DM, Mendelian randomization analysis, which is an epidemiological approach based on the fact that individuals inherit genetic variants randomly from their parents, was conducted.

\section{Methods}

\section{Selection of studies}

All studies that investigated the association of the $677 \mathrm{C}$ $>\mathrm{T}$ polymorphism in the MTHFR gene and Hcy with the development of diabetes were considered in this meta-analysis. We searched the following electronic databases from inception to December 2012: PubMed and web of science databases. As a search criterion, we used the following terms: "MTHFR", "MTHFR 677", "homocysteine", "Hcy”, "diabetes”, “type 2 diabetes", "T2DM", and "polymorphism".

The retrieved publications were then read in their entirety in order to assess their appropriateness for inclusion in this meta-analysis. All references cited in the studies were also reviewed to identify additional published work not indexed by PubMed and web of science databases. Case-control studies that determined the distribution of the MTFHR $677 \mathrm{C}>\mathrm{T}$ genotypes in diabetes and in controls free of diabetes were eligible for inclusion.
Abstracts, editorials, and review articles were excluded. The search was restricted to articles in English.

\section{Data extraction}

Data was carefully extracted from all eligible studies independently by two investigators, and an agreement was reached on all items after discussion with a third investigator. The following information was collected from each study: (1) first author's surname, publication date, subjects' country and ethnicity; and (2) total number, definition and characteristics of cases and controls, and distribution of genotypes and alleles in all groups. For those studies that included subjects of different ethnic groups, data was extracted separately for each of the ethnic groups.

\section{Data analysis and statistical methods}

Hardy-Weinberg equilibrium (HWE) using chi-square test was tested to in control group to determine whether it is in. Studies with controls not in HWE were subjected to a sensitivity analysis.

The meta-analysis examined the overall association of MTHFR $677 \mathrm{C}>\mathrm{T}$ and risk of diabetes; and the contrast of homozygotes $\mathrm{TT}$ versus $\mathrm{CC}$, the contrast $\mathrm{TT}$ versus $(\mathrm{TC}+\mathrm{CC})$, and the contrast $(\mathrm{TT}+\mathrm{TC})$ versus CC. All associations were indicated as odds ratios (OR) with the corresponding 95\% confidence interval (CI). Then, based on the individual OR, a pooled OR was estimated. We used Stata Commands metan to estimate the mean differences for the comparisons of MTHFR 677 TT versus MTHFR 677 CC and for the comparisons of subjects with T2DM versus healthy subjects. To incorporate both withinstudy and between-study variability, we used randomeffects model to calculate the standardized mean difference and $95 \% \mathrm{CI}$ to pool the results for Hcy.

Heterogeneity between studies was tested using the Q-statistic, which is a weighted sum of squares of the deviations of individual study OR estimates from the overall estimate [16]. When the OR were homogeneous, $\mathrm{Q}$ follows a chi-squared distribution with $\mathrm{r}-1$ ( $\mathrm{r}$ is the number of studies) degrees of freedom (df). If $\mathrm{p}<0.05$, then the heterogeneity was considered statistically significant. Heterogeneity was quantified with the $\mathrm{I}^{2}$ metric $\left(\mathrm{I}^{2}=(\mathrm{Q}-\mathrm{df}) / \mathrm{Q}\right)$, which is independent of the number of studies in the meta-analysis [41]. The $\mathrm{I}^{2}$ takes values between $0 \%$ and $100 \%$, with higher values denoting greater degree of heterogeneity $\left(\mathrm{I}^{2}=0-25 \%\right.$, no heterogeneity; $\mathrm{I}^{2}=$ $25-50 \%$, moderate heterogeneity; $\mathrm{I}^{2}=50-75 \%$, large heterogeneity; $\mathrm{I}^{2}=75-100 \%$, extreme heterogeneity). The pooled OR was estimated using fixed effects (Mantel-Haenszel) and random effects models. A random effect model assumes a genuine diversity in the results of various studies, and it incorporates into the calculations a between-study variance. Therefore, when there is heterogeneity between 
studies, then the pooled OR is estimated using the random effects model [16].

The meta-analysis consisted of the main analysis, which includes all available data; the sub-group analysis of ethnic groups. Begg's funnel plot and Egger's regression test (significant at $\mathrm{p}<0.05$ ) were used to evaluate publication bias. Extracted data was analyzed using the Stata, version 11 software (StataCorp, College Station, TX, USA).

Mendelian randomization analysis is based on the concept of Mendelian randomization, that is, the fact that one's genes are inherited before birth by a seemingly random process analogous to treatment allocation in a randomized trial. The Mendelian randomization analysis incorporating information on both the genotype-intermediate phenotype association and genotype-disease association into one analytical framework may allow for an unbiased estimate of the intermediate phenotype-disease association. In the Mendelian randomization paradigm, an instrumental variable has to satisfy the following three criteria $[42,43]$ : 1) the MTHFR $677 \mathrm{C}>\mathrm{T}$ should be robustly associated with Hcy; 2) the genotype should not be associated with confounding factors that bias the association between intermediate Hcy and T2DM; 3) absence of pleiotropy, as the MTHFR $677 \mathrm{C}>\mathrm{T}$ should exert its effect on the T2DM only through the specific intermediate Hcy. Based on available evidence, MTHFR $677 \mathrm{C}>\mathrm{T}$ seemed to meet these assumptions well $[6,39,44,45]$. Thus, the Mendelian randomization coefficient estimates using MTHFR $677 \mathrm{C}>\mathrm{T}$ as instruments would provide the causal association between Hcy and T2DM risk free of bias due to reverse causation and residual confounding. Suppose that the mutant genotype of MTHFR $677 \mathrm{C}>\mathrm{T}$ (TT) is associated with an increased risk of T2DM compared to the wildtype (CC) and that this effect is measured by its odd ratio $\left(\mathrm{OR}_{\mathrm{TT}}\right.$ vs $\left.\mathrm{CC}\right)$. Further suppose that $\mathrm{TT}$ is associated with a mean difference $(\Delta)$ in the level of Hcy compared with $\mathrm{CC}$. $\mathrm{OR}_{1}=\left(\mathrm{OR}_{\mathrm{TT}} \text { vs } \mathrm{CC}\right)^{1 / \Delta}$ is an unconfounded estimate of the OR of T2DM resulting from a unit change in the Hcy. It may be more informative to rescale this OR for increments other than a unit change in Hcy. For an increment of $\mathrm{k}$ units the formula becomes $\mathrm{OR}_{\mathrm{k}}=\left(\mathrm{OR}_{\mathrm{TT}} \text { vs } \mathrm{CC}\right)^{\mathrm{k} / \Delta}[46]$, in this analysis, we used $5 \mu \mathrm{mol} / \mathrm{l}$ increase in serum Hcy to calculate the OR [47].

\section{Results}

\section{Summary statistics}

The seventeen studies provided 4011 cases and 4303 controls [12,25-40] (Figure 1). The allele $C$ was the most common. The frequencies of the CC genotype were the highest in controls and in cases, while that for genotype TT was the lowest. Three studies only reported the association between blood Hcy level and MTHFR $677 \mathrm{C}>\mathrm{T}$ in diabetes patients [48-50]. In three studies [34-36], the distribution of the genotypes in the control group was not in HWE $(\mathrm{p}<0.05)$ (Table 1$)$.

\section{Pooled difference in mean Hcy level between MTHFR genotypes in type 2 diabetes patients}

Eleven studies (2498 T2DM) [12,25,30,31,35,38,39,48-50] were identified that satisfied inclusion criteria and expressed the between-group difference in plasma Hcy level in terms of the arithmetic mean and standard deviation. In all these studies, the mean Hcy concentration was greater in subjects with MTHFR 677TT than in those with the other two genotypes. The absolute pooled mean Hcy concentration in subjects with MTHFR 677TT was $5.55 \mu \mathrm{mol} / \mathrm{L}$ (95\% CI, 1.33 to 9.77 ) greater than that in subjects with MTHFR 677CC $(\mathrm{p}=0.012)$ (Figure 2). While, the subjects with MTHFR 677TT had $4.06 \mu \mathrm{mol} / \mathrm{L}$ higher Hcy concentration than subjects with MTHFR 677CT $(\mathrm{p}=0.008)$ (Figure 3$)$. The sensitivity analysis regarding the MTHFR $677 \mathrm{C}>\mathrm{T}$ not being in HWE did not significant change the results.

\section{The association between MTHFR $677 \mathrm{C}>\mathrm{T}$ and risk of type 2 diabetes}

The main analysis for investigating the association between MTHFR 677TT and risk of developing T2DM relative to the $677 \mathrm{CC}$ revealed significant heterogeneity ( $\mathrm{p}$ for heterogeneity $=0.035, \mathrm{I}^{2}=43 \%$ ) between 17 studies; the random effect (RE) pooled OR was significant: $\mathrm{RE} O \mathrm{OR}=1.33(1.05-1.67)(\mathrm{p}=0.021)$ (Figure 4). Overall, the $\mathrm{T}$ allele of the MTHFR $677 \mathrm{C}>\mathrm{T}$ conferred a greater risk for T2DM $\left[R E O R=1.31(1.05-1.64)(\mathrm{p}=0.032), \mathrm{I}^{2}=\right.$ $41.0 \%, \mathrm{p}$ for heterogeneity $=0.055$ ] (Figure 5). The random-effect pooled OR of the association for MTHFR 677 TT vs CT was 1.29 (95\% CI, 1.09-1.51) ( $\mathrm{p}=0.021$ ). MTHFR 677 TT showed a significantly higher risk for T2DM compared with MTHFR $677 \mathrm{CC}+\mathrm{CT}$ [Fixed effect $(\mathrm{FE}) \mathrm{OR}=1.32(1.14-1.54) \quad(\mathrm{p}=0.034), \mathrm{I}^{2}=0.0 \%$, $\mathrm{p}$ for heterogeneity $=0.686]$. MTHFR $677 \mathrm{TT}+\mathrm{CT}$ also showed a significantly higher risk for T2DM compared with MTHFR 677 CC [RE OR=1.12 (1.07-1.34) $(\mathrm{p}=$ $0.029), \mathrm{I}^{2}=42.0 \%, \mathrm{p}$ for heterogeneity $\left.=0.046\right]$. Subgroup analysis was also performed to ensure that the application of the method of estimating the causal effect is unbiased. Subgroup analysis was grouped by studies that reported results on both associations (MTHFR $677 \mathrm{C}>\mathrm{T}$-T2DM effects and MTHFR $677 \mathrm{C}>\mathrm{T}$-Hcy effects) and by those reported only a single association result. The results showed similar significant effect sizes between both groups (both: 1.44 (0.93-2.23), Single: 1.35 (1.03-1.75).

\section{The associations between plasma Hcy and type 2 diabetes}

Figure 6 showed a forest plot of standardized mean difference (SMD) in Hcy between subjects with and 


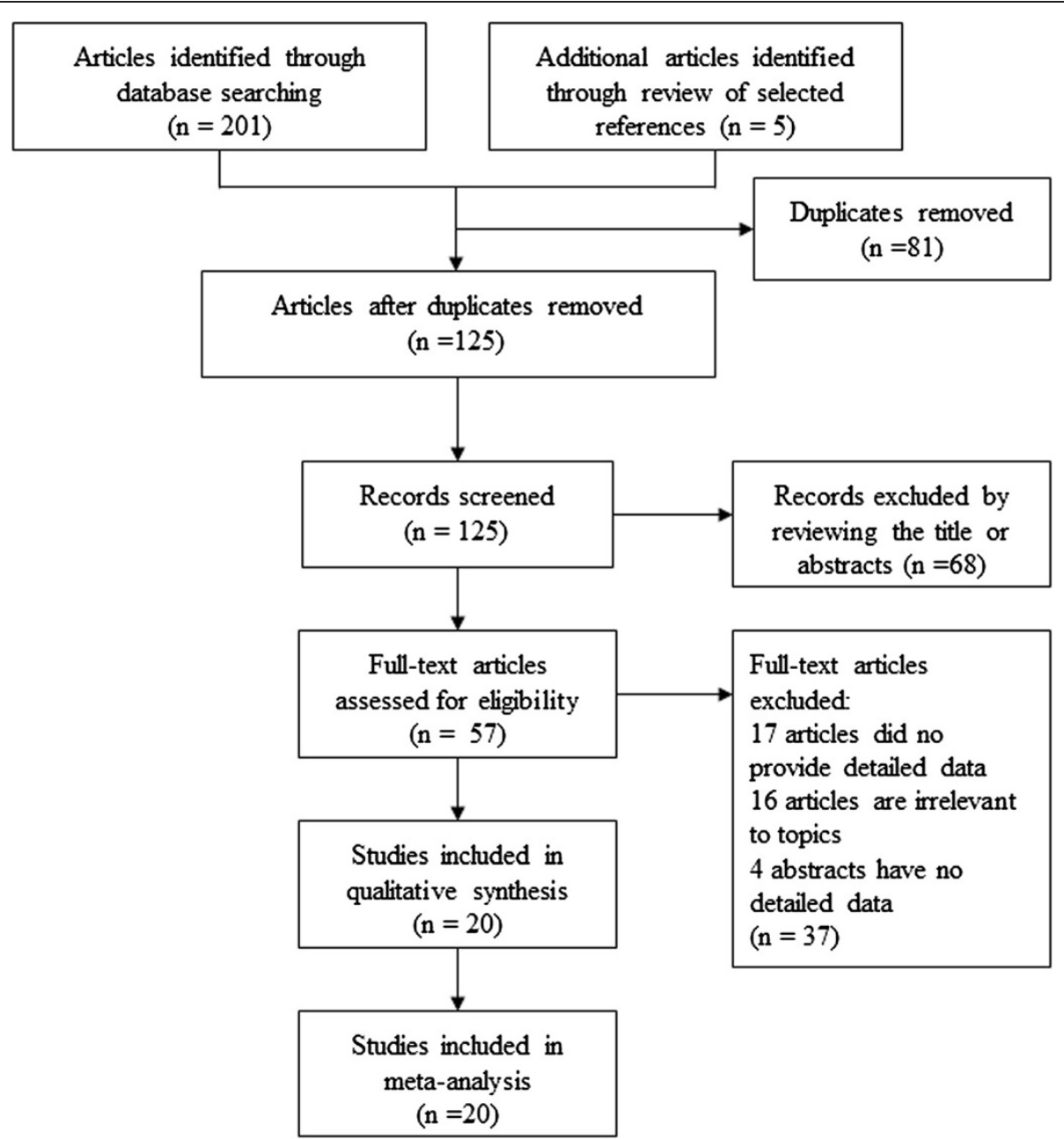

Figure 1 PRISMA flow diagram for selection of studies in the meta-analysis.

without T2DM in included studies. The main analysis for this association revealed significant heterogeneity ( $\mathrm{p}$ for heterogeneity $<0.001, \mathrm{I}^{2}=98.0 \%$ ) between the studies. In 14 of these studies [7,8,12,13,25,30,33,35,40,51-54], the mean Hcy concentration was greater in patients with T2DM than in control subjects (Figure 6). The absolute pooled mean Hcy concentration in patients with T2DM was $0.94 \mu \mathrm{mol} / \mathrm{L}(95 \% \mathrm{CI}, 0.40-1.48)$ greater than that in control subjects in random model $(\mathrm{p}=0.017)$. We further conducted a subgroup analysis of ethnic groups, all results from Europe, Asia and Africa showed significant differences in Hcy levels between subjects with or without T2DM. Additionally, subgroup analysis was also grouped by studies that reported results on both associations (MTHFR $677 \mathrm{C}>\mathrm{T}$-T2DM effects and MTHFR $677 \mathrm{C}>\mathrm{T}$ Hcy effects) and by those reported only a single association result. The results showed similar significant effect sizes between both groups (both: 5.94 (0.30-11.59), Single: 3.03 (-0.02-6.08). In addition, Begg's and Egger's tests did not show evidence for the presence of substantial publication bias for the Hcy-T2DM association in different inheritance models (data not shown).

\section{Causal association of Hcy with risk of type 2 diabetes by Mendelian randomization}

Figure 7 showed the predicted OR of T2DM associated with per unit increase in direct or indirect measures of Hcy using MTHFR $677 \mathrm{C}>\mathrm{T}$ as an instrumental variable for Hcy. Increased Hcy levels were strongly associated with increased risk of type 2 diabetes. The estimated causal OR for $5 \mu \mathrm{mol} / \mathrm{L}$ Hcy increment was 1.29 (1.04-1.59).

\section{Discussions}

Overall, we found that MTHFR $677 \mathrm{~T}$ was significantly associated with elevated plasma Hcy concentration. The pooled mean Hcy concentration was greater in subjects with T2DM than in those without T2DM. Our findings from Mendelian randomization approach supported the hypothesis that elevated Hcy is causally related to increased risk of T2DM. 
Table 1 The distribution of the MTHFR 677 C > T genotype for case and control and the allele frequencies

\begin{tabular}{|c|c|c|c|c|c|c|c|c|c|c|c|c|c|}
\hline \multirow[t]{3}{*}{ First author } & \multirow[t]{3}{*}{ Year } & \multirow{3}{*}{$\begin{array}{l}\text { Ethnical } \\
\text { decent }\end{array}$} & \multicolumn{6}{|c|}{ Distribution of MTHFR genotypes (n(\%)) } & \multicolumn{4}{|c|}{ Frequency of $M T H F R$ alleles (\%) } & \multirow[t]{3}{*}{ P-valueHWE } \\
\hline & & & \multicolumn{2}{|l|}{$\overline{\mathrm{CC}}$} & \multicolumn{2}{|l|}{ CT } & \multicolumn{2}{|l|}{$\mathrm{TT}$} & \multicolumn{2}{|l|}{$\mathrm{C}$} & \multicolumn{2}{|l|}{$T$} & \\
\hline & & & Case & Control & Case & Control & Case & Control & Case & Control & Case & Control & \\
\hline Ndrepepa et al. [25] & 2008 & Germany & $225(44)$ & $690(43)$ & 215(42) & $740(46)$ & $67(13)$ & 184(11) & / & / & / & / & 0.49 \\
\hline Mazza et al. [12] & 2005 & Italy & $35(33)$ & $35(29)$ & $47(45)$ & $66(55)$ & 23(22) & 19(16) & / & / & / & / & 0.19 \\
\hline Bluthner et al. [26] & 1999 & Poland & $137(47)$ & $67(45)$ & $115(39)$ & $68(45)$ & $41(13)$ & $15(10)$ & / & 67 & / & 33 & 0.71 \\
\hline Benes et al. [27] & 2001 & Czech & $166(48)$ & $86(41)$ & $152(43)$ & $106(51)$ & $31(8)$ & $17(8)$ & 69 & 67 & 31 & 33 & 0.05 \\
\hline Yilmaz et al. [28] & 2004 & Turkish & $121(49)$ & $101(47)$ & 98(39) & $93(44)$ & $30(12)$ & 20(9) & 68 & 69 & 32 & 31 & 0.83 \\
\hline Eroglu et al. [29] & 2007 & Turkish & $51(50)$ & $63(49)$ & $45(44)$ & $58(45)$ & $7(7)$ & $7(6)$ & 71 & 71 & 29 & 29 & 0.17 \\
\hline Tutuncu et al. [30] & 2005 & Turkey & $41(45)$ & $52(52)$ & $39(43)$ & $43(43)$ & $11(12)$ & $5(5)$ & 60 & 70 & 40 & 30 & 0.29 \\
\hline Soares et al. [31] & 2007 & UK & $10(55)$ & $9(56)$ & $6(33)$ & $5(31)$ & $2(11)$ & $2(13)$ & / & / & / & / & 0.36 \\
\hline Angeline et al. [32] & 2009 & Indian & $88(73)$ & $80(80)$ & $32(27)$ & $20(20)$ & 0 & 0 & 88 & 90 & 12 & 10 & 0.57 \\
\hline Mehri et al. [33] & 2010 & Tunisian & $50(43)$ & $66(57)$ & $49(43)$ & $38(33)$ & $16(14)$ & $12(10)$ & 65 & 73 & 35 & 27 & 0.07 \\
\hline Sun et al. [34] & 2004 & Chinese & 102(46) & $74(57)$ & $76(35)$ & $34(26)$ & $42(19)$ & $22(17)$ & 64 & 70 & 56 & 30 & 0.001 \\
\hline Mtiraoui et al. [35] & 2007 & Tunisia & $163(45)$ & $270(68)$ & 135(38) & $94(24)$ & $62(17)$ & $36(9)$ & 64 & 79 & 36 & 21 & 0 \\
\hline Sun et al. [36] & 2003 & Chinese & $84(40)$ & $31(54)$ & $75(36)$ & $16(28)$ & $49(24)$ & 10(18) & 58 & 68 & 42 & 32 & 0.01 \\
\hline Movva, et al. [37] & 2011 & Indian & $68(68)$ & $91(91)$ & $32(32)$ & $9(9)$ & 0 & 0 & 84 & 95 & 16 & 4 & 0.05 \\
\hline $\begin{array}{l}\text { Tavakkoly } \\
\text { Bazzaz et al. [38] }\end{array}$ & 2010 & Iran & 148(53) & 113(55) & $102(36)$ & 80(39) & $31(11)$ & $14(7)$ & 71 & 76 & 26 & 24 & 0.21 \\
\hline Benrahma et al. [39] & 2012 & Morocco & $160(57)$ & $114(44)$ & $97(35)$ & $122(47)$ & $25(9)$ & $26(10)$ & 74 & 67 & 26 & 33 & 0.19 \\
\hline Sharaf et al. [40] & 2012 & Egypt & $24(48)$ & $13(65)$ & $17(34)$ & $5(25)$ & $9(18)$ & $2(10)$ & 65 & 78 & 35 & 22 & 0.13 \\
\hline
\end{tabular}

The significance level ( $p$-value) for Hardy-Weinberg equilibrium (HWE) testing for controls is shown.

Previous studies have given conflicting results regarding the circulating Hcy levels in patients with diabetes. An association between Hcy level and diabetic complications was seen in type I diabetes, but not among T2DM [7]. Very recently, a study on 105 patients with T2DM and normal renal function also found that in patients with T2DM, basal level of Hcy was 35\% lower compared with healthy subjects [12]. The reduced Hcy level may be explained by an influence of hyperglycemia on acceleration in the hepatic transsulfuration pathway due to insulin disorder [12], subsequently, elevated glucocorticoids decreased Hcy level [55]. Cell culture and animal studies also showed that the diabetic status may reduce rather than increase the circulating Hcy level due to enhanced Hcy catabolism [55,56]. However, it should be emphasized that this data was derived from animal models of experimental diabetes and cannot provide solid evidence that a similar relationship between diabetic status and Hcy level exists in patients with diabetes. Moreover, many other studies found that plasma Hcy levels were significantly higher in diabetic patients than in subjects without diabetes. In the present metaanalysis, the main analysis for weighted mean difference in Hcy between subjects with and without T2DM in all included studies revealed significant heterogeneity between the studies. Therefore, we used random model to estimate the pooled mean Hcy. Similarly, the absolute pooled mean Hcy concentration in individuals with T2DM was also significantly higher than that in control subjects in random model. We speculated that a large part of the discrepancy resulted from the heterogeneity of patients included in these studies with regard to the stage of disease, status of renal function or presence of macroangiopathy $[4,9]$. Furthermore, the opposing influences on circulating Hcy levels exercised by the diabetic status per se and by a number of risk factors that relate to or are accentuated by diabetes may also help explain the controversy [25].

Importantly, the heterogeneity may also result from the genetic background of the patients. A common variant (MTHFR $677 \mathrm{C}>\mathrm{T}$ ) of the enzyme MTHFR involved in the Hcy metabolic pathway may affect Hcy concentration [57]. Among the diabetic group, patients carrying the $\mathrm{T}$ allele showed a increased Hcy level in comparison to those having the native genotype CC [23]. This contradicted a previous report which suggested that double heterozygosity was associated with reduced enzyme activity and high Hcy level [58]. Interestingly, the MTHFR $677 \mathrm{C}>\mathrm{T}$ appears to have a sex-specific effect on Hcy, Hcy level was slightly higher in men than in women [59]. Men carrying TT genotype appear to be at higher risk of HHcy than women with this genotype [60]. Plasma estrogen was found to decrease in MTHFR CC, but not in TT homozygous postmenopausal women [61]. The precise 


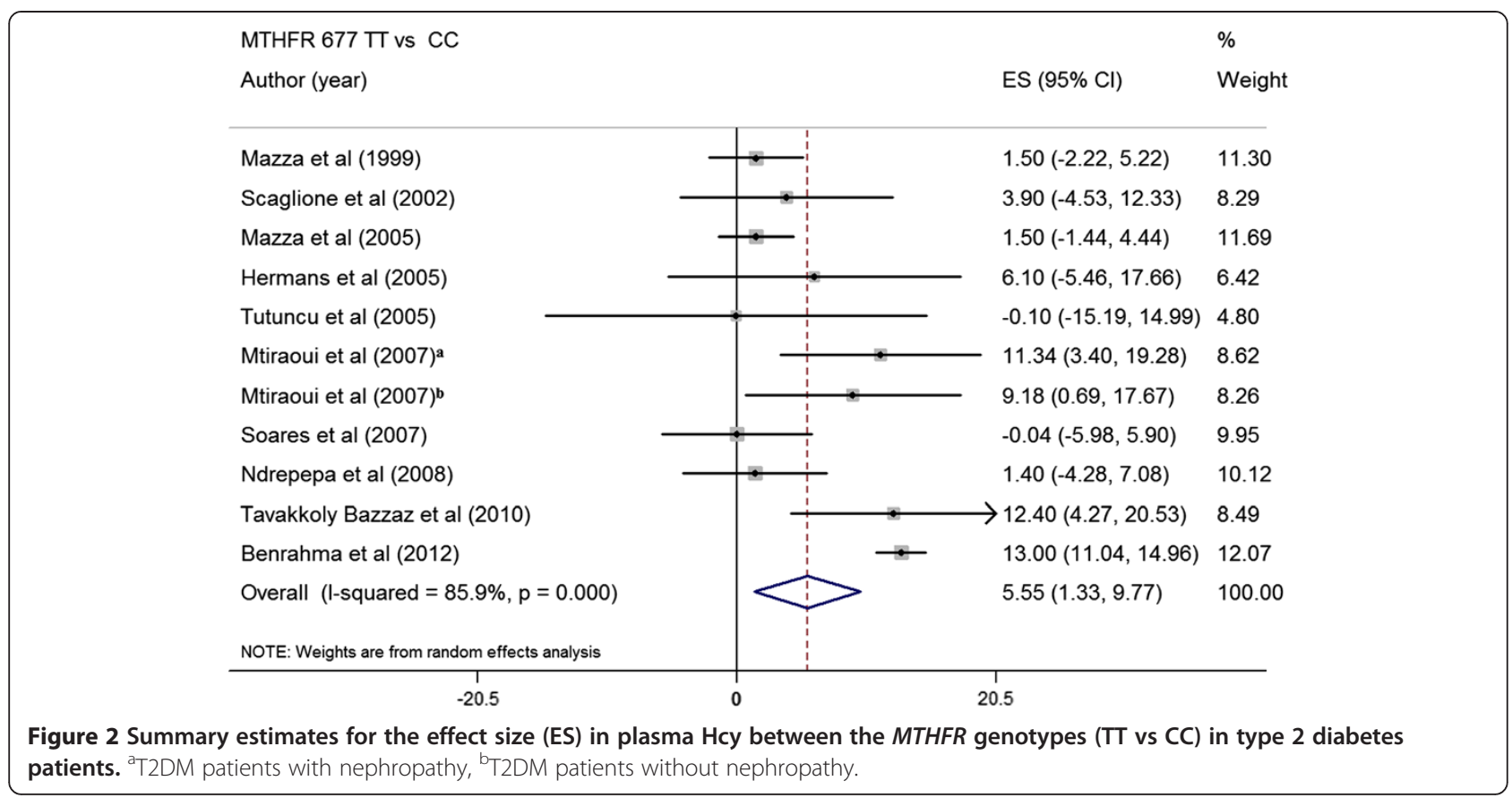

mechanism by which estrogen could affect Hcy metabolism is not known. But the sex-specific effect may contribute to the previous contradicted results. Our meta-analysis gave strong evidence that the MTHFR was associated with plasma Hcy in patients with T2DM. MTHFR 677TT have significantly higher plasma Hcy than other genotypes, which are consistent with previous results in diabetic subjects [25].
Because elevated plasma Hcy level in patients with T2DM has been reported, it may be readily postulated that the $677 \mathrm{C}>\mathrm{T}$ MTHFR gene polymorphism might be involved in the development of T2DM [23]. However, no literature data directly associates the MTHFR-linked Hcy metabolism with T2DM. To date, the relationship between the MTHFR $677 \mathrm{C}>\mathrm{T}$ polymorphism and T2DM is less clear. Previous studies found an association between

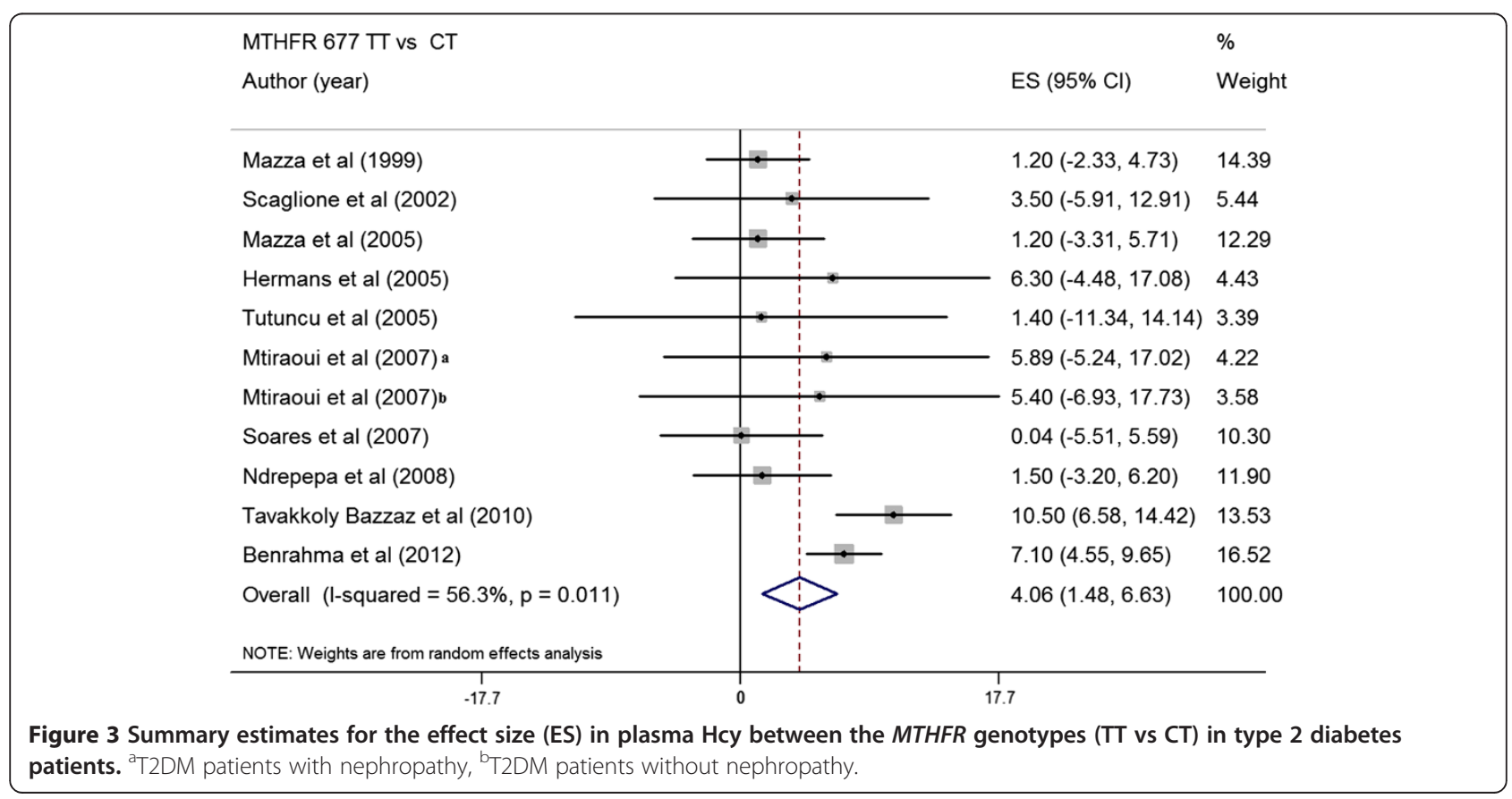




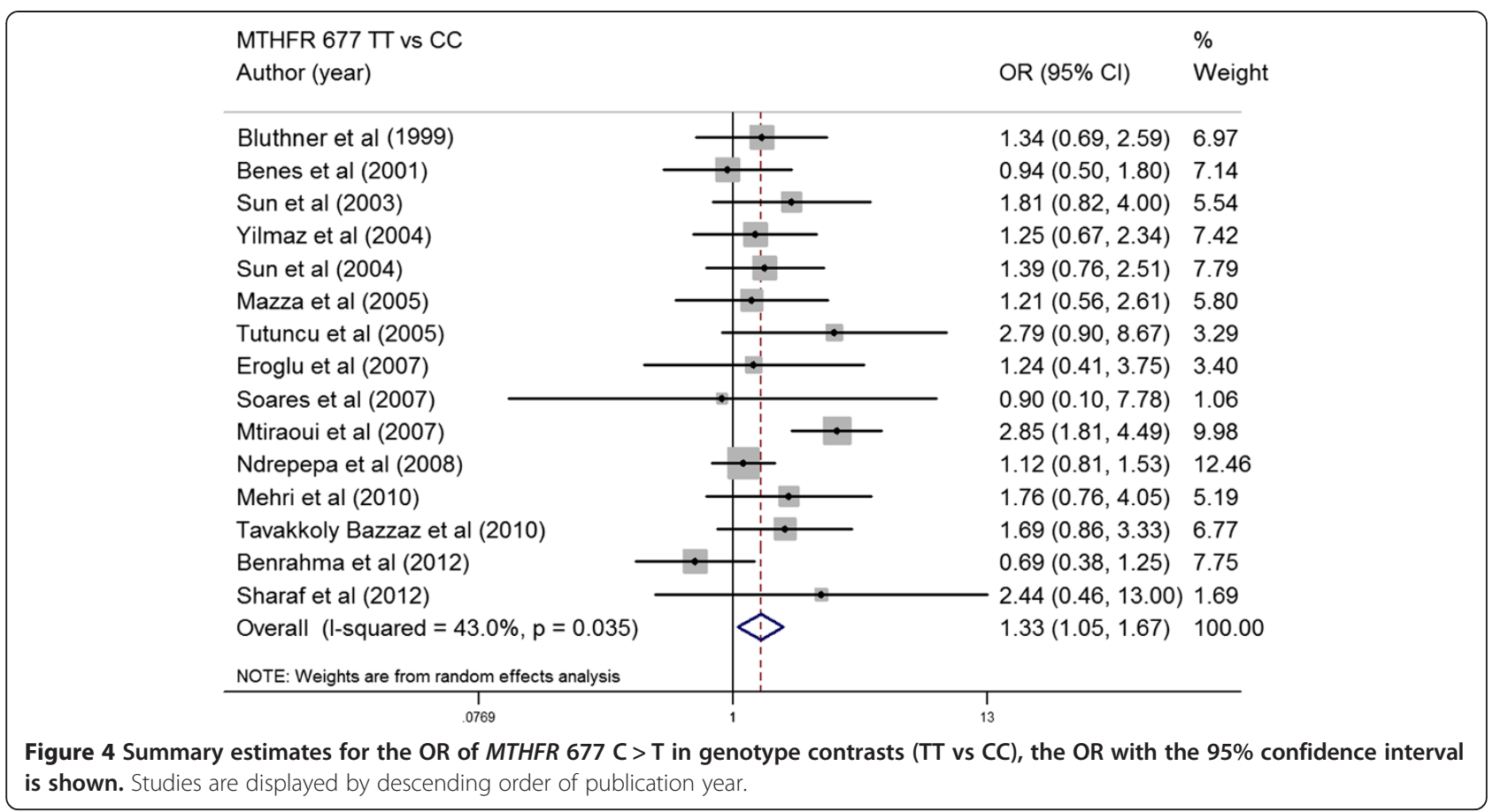

mutant homozygous genotype for MTHFR $677 \mathrm{C}>\mathrm{T}$ and diabetic retinopathy in individuals with T2DM [62]. Similarly, another study has also found that the MTHFR $677 \mathrm{C}$ $>\mathrm{T}$ predisposes T2DM patients to the development of diabetic retinopathy [63]. One study suggested the MTHFR mutant genotype as a possible risk factor for the development of left ventricular hypertrophy in T2DM [28]. The $\mathrm{TT}$ genotype was more frequent in T2DM patients than in healthy controls (13.9\% vs. 10.3\%). Of interest is that the Brazilian population holds the lowest frequency ever reported for the TT genotype (9\%) [53], and the highest (19.1\%) is in Chinese population [34]. In fact, the association between the MTHFR $677 \mathrm{C}>\mathrm{T}$ and diabetes was not found in some studies including Brazil [53], China [34], Germany [25]. The reasons why there are conflicting results in studies concerning MTHFR677 C > T and T2DM

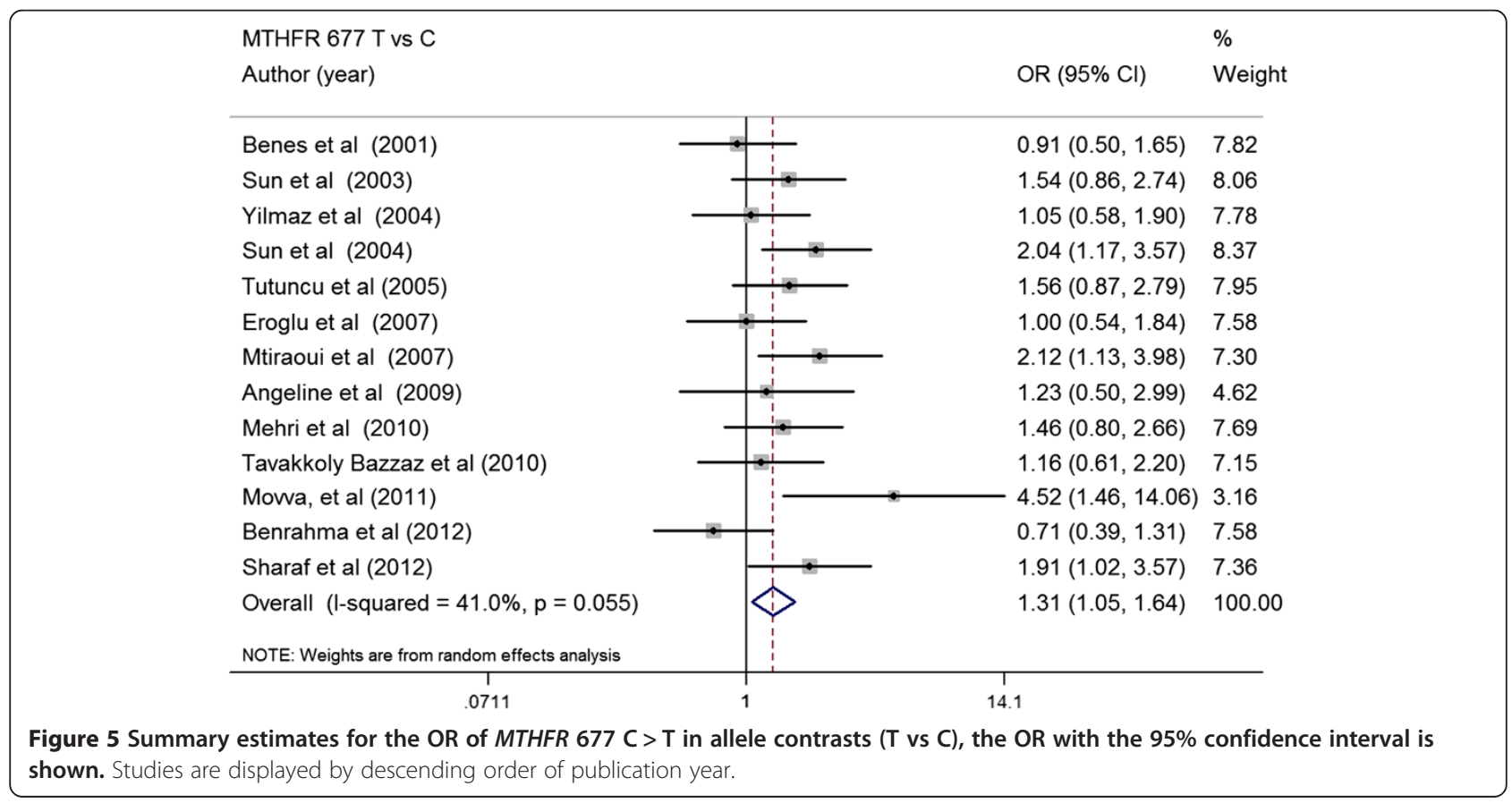




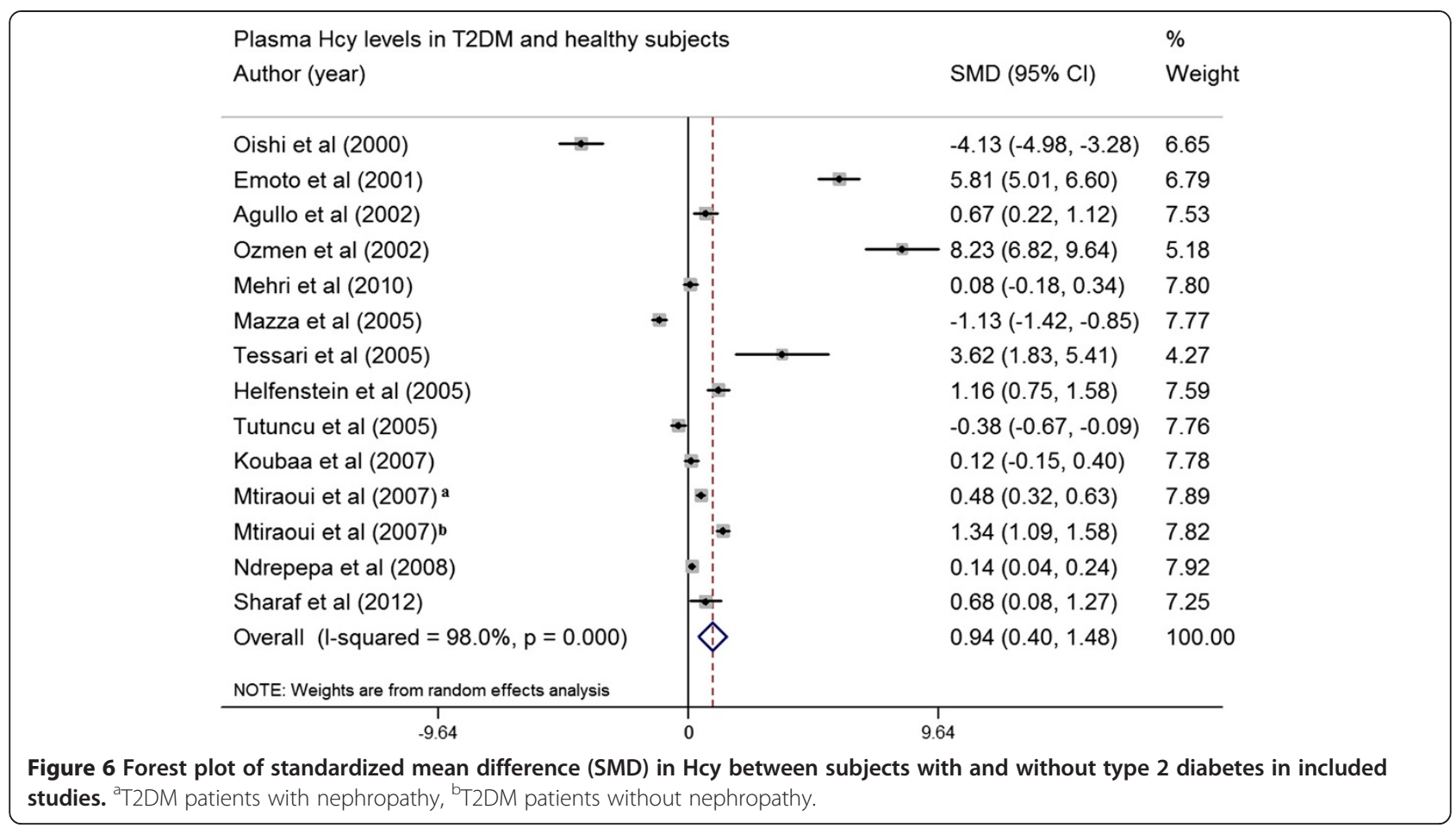

are still not understood, however, an important reason for conflicting results may relate to the different genetic background of patients included in the studies. The frequency of MTHFR 677TT varies in different ethnic groups, for example, the 677TT genotype frequency is the lowest in Moroccan patients and controls $(8.87 \%$ and $9.92 \%$, respectively) [39]. Similarly, low frequency of $677 \mathrm{TT}$ (9\%) was also reported in a Brazilian population [53]. In contrast, a high frequency (19.1\%) of the 677TT genotype was reported in a Chinese population [34]. Furthermore, small sample size, study design flaws or other biases may be more common reasons than true racial heterogeneity for the observed discrepancies between studies

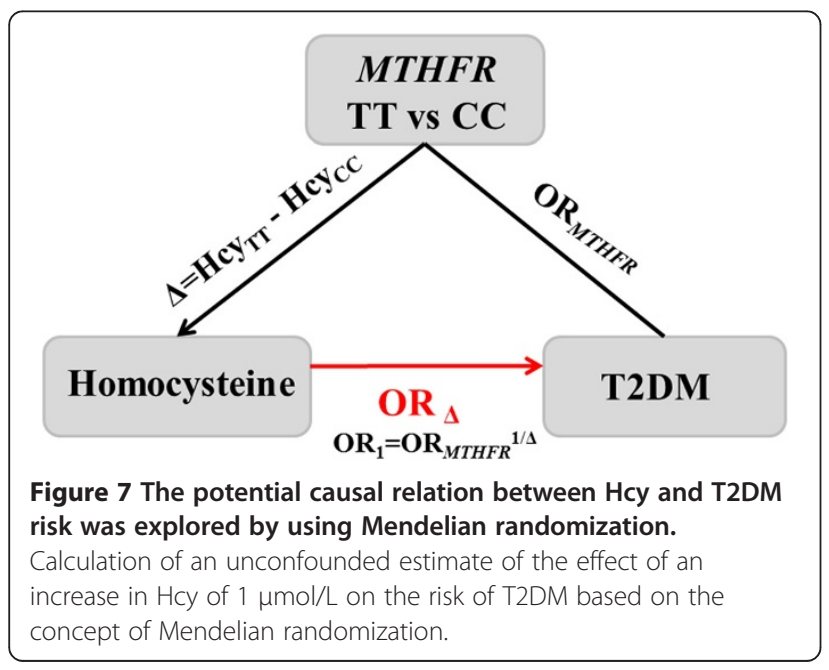

addressing genetic risks $[64,65]$. The meta-analysis presented here included data from case-control association studies that investigated the relationship between MTHFR polymorphism and T2DM. The strength of the present analysis, however, is based on the aggregation of published case-control studies. The overall results indicated an association of MTHFR $677 \mathrm{C}>\mathrm{T}$ with T2DM and MTHFR TT genotype increases the risk of T2DM.

Our study is the first meta-analysis to date which has pooled all the data available to investigate the associations of MTHFR-linked Hcy and T2DM. Therefore we have provided the most extensive data on this issue. As with all meta-analyses, some limitations are also presented here. First, the lack of clinical homogeneity between the subjects in the included studies, although our inclusion criteria ensured that the selected studies were broadly similar, it was not possible to eliminate all sources of heterogeneity. Second, we pooled the data from different ethnicities together, genetic heterogeneity among diverse ethnic populations leads to some unavoidable bias. Third, many studies did not include information regarding vitamin status at the time of Hcy measurement, which prevented examination of the interaction between nutritional status, Hcy, genotypes, and diabetic risk. Differences in sampling protocols and methods of Hcy measurement may have contributed to variation between studies. Hcy measurement using different high-performance liquid chromatography methods has been reported to vary by 6 to $7 \%$ among different laboratories [66]. Fourthly, exclusion of studies which didn't provide adequate information 
might contribute to the publication bias. We also cannot exclude the possibility of bias related to the exclusion of non-English language publications, although Begg's and Egger's tests did not show evidence for the presence of substantial publication bias with respect to the small effect sizes. Fifthly, although we observed elevated Hcy is causally related to increased risk of T2DM, recent clinical trial showed that lowering Hcy levels by daily supplementation with folic acid and vitamins $\mathrm{B}_{6}$ and $\mathrm{B}_{12}$ did not reduce the risk of developing T2D among women at high risk for CVD [67]. We specialated that the associations of Hcy with T2D may be modified by environmental factors such as dietary folate, as well as the potential gene-environment interactions involved in the development of T2D. Finally, the association of the MTHFR variant with T2D was not observed in large-scale GWAS studies with huge sample sizes. The possible reason is that this association is likely to be due to the combined effect of genes, environmental factors, and their interactions. However, most investigators conducting GWAS do not consider gene-environment interactions in their search for new genes due to a current lack of efficient statistical methods for detecting interactions in high-volume genetic data.

\section{Conclusions}

In summary, our results provided evidence that the TT genotype of MTHFR C677T contributes to susceptibility to T2DM, and supported the hypothesis that elevated Hcy is causally related to increased risk of T2DM. The existence of gene-environment interactions may explain the discrepancy of results obtained in individual genetic association studies. Therefore, case-control studies that investigate gene-environment interactions might help further elucidate the genetics of T2DM.

\section{Consent}

Written informed consent was obtained from the patient for the publication of this report and any accompanying images.

\section{Competing interests}

The authors declare that they have no competing interests.

\section{Authors' contributions}

$T H, J R$, and DL designed research; $T H, J R$ analyzed data; $T H, L R$, JH wrote the paper. DL had primary responsibility for final content. All authors read and approved the final manuscript.

\section{Acknowledgement}

The study was funded by National Natural Science Foundation of China (NSFC, no. 81273054), National Basic Research Program of China (973 Program: 2011CB504002), and the Ph.D. Programs Foundation of Ministry of Education of China (20120101110107).

\section{Author details}

${ }^{1}$ Department of International Health, Johns Hopkins Bloomberg School of Public Health, Baltimore, MD 21205, USA. ${ }^{2}$ Department of Food Science and Nutrition, Zhejiang University, 268 Kaixuan Road, Hangzhou 310029, China.

${ }^{3}$ APCNS Centre of Nutrition and Food Safety, Hangzhou, China. ${ }^{4}$ The First
Affiliated Hospital, Medical College, Zhejiang University, Hangzhou, China. ${ }^{5}$ Department of Biostatistics, Harvard School of Public Health, Boston, MA 02115, USA.

Received: 14 July 2013 Accepted: 27 November 2013

Published: 10 December 2013

\section{References}

1. King GL, Kunisaki M, Nishio Y, Inoguchi T, Shiba T, et al: Biochemical and molecular mechanisms in the development of diabetic vascular complications. Diabetes 1996, 45:S105-S108.

2. Hoogeveen EK, Kostense PJ, Beks PJ, MacKaay AJC, Jakobs C, et al: Hyperhomocysteinemia is associated with an increased risk of cardiovascular disease, especially in non-insulin-dependent diabetes mellitus - a population-based. Arterioscler Thromb Vasc Biol 1998, 18:133-138.

3. Meigs JB, Jacques PF, Selhub J, Singer DE, Nathan DM, et al: Fasting plasma homocysteine levels in the insulin resistance syndrome - the Framingham offspring study. Diabetes Care 2001, 24:1403-1410.

4. Buysschaert M, Dramais AS, Wallemacq PE, Hermans MP: Hyperhomocysteinemia in type 2 diabetes: relationship to macroangiopathy, nephropathy, and insulin resistance. Diabetes Care 2000, 23:1816-1822.

5. Kark JD, Selhub J, Bostom A, Adler B, Rosenberg $\Vdash$ : Plasma homocysteine and all-cause mortality in diabetes. Lancet 1999, 353:1936-1937.

6. Hoogeveen EK, Kostense PJ, Jakobs C, Dekker JM, Nijpels G, et al: Hyperhomocysteinemia increases risk of death, especially in type 2 diabetes - 5-year follow-up of the Hoorn study. Circulation 2000, 101:1506-1511.

7. Agullo-Ortuno MT, Albaladejo MD, Parra S, Rodriguez-Manotas M, Fenollar $\mathrm{M}$, et al: Plasmatic homocysteine concentration and its relationship with complications associated to diabetes mellitus. Clin Chim Acta 2002, 326:105-112.

8. Emoto M, Kanda H, Shoji T, Kawagishi T, Komatsu M, et al: Impact of insulin resistance and nephropathy on homocysteine in type 2 diabetes. Diabetes Care 2001, 24:533-538.

9. Smulders YM, Rakic M, Slaats EH, Treskes M, Sijbrands EJ, et al: Fasting and post-methionine homocysteine levels in NIDDM. Determinants and correlations with retinopathy, albuminuria, and cardiovascular disease. Diabetes Care 1999, 22:125-132.

10. Araki A, Sako Y, Ito H: Plasma homocysteine concentrations in Japanese patients with non-insulin-dependent diabetes mellitus: effect of parenteral methylcobalamin treatment. Atherosclerosis 1993, 103:149-157.

11. Folsom AR, Nieto FJ, McGovern PG, Tsai MY, Malinow MR, et al: Prospective study of coronary heart disease incidence in relation to fasting total homocysteine, related genetic polymorphisms, and B vitamins: the Atherosclerosis Risk in Communities (ARIC) study. Circulation 1998, 98:204-210.

12. Mazza A, Bossone E, Mazza F, Distante A: Reduced serum homocysteine levels in type 2 diabetes. Nutr Metab Cardiovasc Dis 2005, 15:118-124.

13. Oishi $K$, Nagake $Y$, Yamasaki $H$, Fukuda S, Ichikawa $H$, et al: The significance of serum homocysteine levels in diabetic patients on haemodialysis. Nephrol Dial Transplant 2000, 15:851-855.

14. Lander ES: The new genomics: global views of biology. Science 1996, 274:536-539.

15. Jacques PF, Bostom AG, Williams RR, Ellison RC, Eckfeldt JH, et al: Relation between folate status, a common mutation in methylenetetrahydrofolate reductase, and plasma homocysteine concentrations. Circulation 1996, 93:7-9.

16. Zintzaras E, Chatzoulis DZ, Karabatsas CH, Stefanidis I: The relationship between $\mathrm{C677T}$ methylenetetrahydrofolate reductase gene polymorphism and retinopathy in type 2 diabetes: a meta-analysis. J Hum Genet 2005, 50:267-275

17. Hemati T, Moghadami-Tabrizi N, Davari-Tanha F, Salmanian B, Javadian P. High plasma homocysteine and insulin resistance in patients with polycystic ovarian syndrome. Iranian Journal of Reproductive Medicine 2011, 9:223-228.

18. Nafiye $Y$, Sevtap $K$, Muammer D, Emre $O$, Senol $K$, et al: The effect of serum and intrafollicular insulin resistance parameters and homocysteine levels of nonobese, nonhyperandrogenemic polycystic ovary syndrome patients on in vitro fertilization outcome. Fertil Steril 2010, 93:1864-1869. 
19. Malek-Khosravi S, Kaboudi M, Kaboudi B, Atefi G: Plasma homocysteine concentrations and insulin resistance in preeclampsia. Hypertens Pregnancy 2009, 28:13-22.

20. Patterson S, Flatt PR, Brennan L, Newsholme P, McClenaghan NH: Detrimental actions of metabolic syndrome risk factor, homocysteine, on pancreatic beta-cell glucose metabolism and insulin secretion. J Endocrinol 2006, 189:301-310.

21. Patterson S, Flatt PR, McClenaghan NH: Homocysteine-induced impairment of insulin secretion from clonal pancreatic BRIN-BD11 beta-cells is not prevented by catalase. Pancreas 2007, 34:144-151.

22. Scullion SMJ, Gurgul-Convey E, Elsner M, Lenzen S, Flatt PR, et al: Enhancement of homocysteine toxicity to insulin-secreting BRIN-BD11 cells in combination with alloxan. J Endocrinol 2012, 214:233-238.

23. Russo GT, Di Benedetto A, Magazzù D, Giandalia A, Giorda CB, et al: Mild hyperhomocysteinemia, C677T polymorphism on methylenetetrahydrofolate reductasegene and the risk of macroangiopathy in type 2 diabetes: a prospective study. Acta Diabetol 2011, 48:95-101.

24. Kelly PJ, Rosand J, Kistler JP, Shih VE, Silveira S, et al: Homocysteine, MTHFR 677CT polymorphism, and risk of ischemic stroke: results of a meta-analysis. Neurology 2002, 59:529-536.

25. Ndrepepa G, Kastrati A, Braun S, Koch W, Kolling K, et al: Circulating homocysteine levels in patients with type 2 diabetes mellitus. Nutr Metab Cardiovasc Dis 2008, 18:66-73.

26. Bluthner M, Bruntgens A, Schmidt S, Strojek K, Grzeszczak W, et al: Association of methylenetetrahydrofolate reductase gene polymorphism and diabetic nephropathy in type 2 diabetes? Nephrol Dial Transplant 1999, 14:56-57.

27. Benes P, Kankova K, Muzik J, Groch L, Benedik J, et al: Methylenetetrahydrofolate reductase polymorphism, type II diabetes mellitus, coronary artery disease, and essential hypertension in the Czech population. Mol Genet Metab 2001, 73:188-195.

28. Yilmaz H, Agachan B, Ergen A, Karaalib ZE, Isbir T: Methylene tetrahydrofolate reductase C677T mutation and left ventricular hypertrophy in Turkish patients with type II diabetes mellitus. J Biochem Mol Biol 2004, 37:234-238.

29. Erdogan M, Karadeniz M, Eroglu Z, Tezcanli B, Selvi N, et al: The relationship of the peroxisome proliferator-activated receptor-gamma 2 exon 2 and exon 6 gene polymorphism in Turkish type 2 diabetic patients with and without nephropathy. Diabetes Res Clin Pract 2007, 78:355-359.

30. Tutuncu NB, Erbas T, Alikasifoglu M, Tuncbilek E: Thermolabile methylenetetrahydrofolate reductase enzyme genotype is frequent in type 2 diabetic patients with normal fasting homocysteine levels. J Intern Med 2005, 257:446-453.

31. Soares AL, Fernandes AP, Cardoso JE, Sousa MO, Lasmar MC, et al: Plasma total homocysteine levels and methylenetetrahydrofolate reductase gene polymorphism in patients with type 2 diabetes mellitus. Pathophysiol Haemost Thromb 2007, 36:275-281.

32. Angeline T, Thiruvarutselvi G, Isabel W, Aruna RM, Devi R, et al: MTHFR (Ala 222 Val) polymorphism and AMI in patients with type II diabetes mellitus. Indian J Clin Biochem 2009, 24:137-141.

33. Mehri S, Koubaa N, Nakbi A, Hammami S, Chaaba R, et al: Relationship between genetic polymorphisms of angiotensin-converting enzyme and methylenetetrahydrofolate reductase as risk factors for type 2 diabetes in Tunisian patients. Clin Biochem 2010, 43:259-266.

34. Sun JH, Xu YC, Zhu YL, Lu HY: Genetic polymorphism of methylenetetrahydrofolate reductase as a risk factor for diabetic nephropathy in Chinese type 2 diabetic patients. Diabetes Res Clin Pract 2004, 64:185-190.

35. Mtiraoui N, Ezzidi I, Chaieb M, Marmouche H, Aouni Z, et al: MTHFR C677T and $\mathrm{A} 1298 \mathrm{C}$ gene polymorphisms and hyperhomocysteinemia as risk factors of diabetic nephropathy in type 2 diabetes patients. Diabetes Res Clin Pract 2007, 75:99-106.

36. Sun J, Xu Y, Zhu Y, Lu H, Deng $H$, et al: The relationship of methylenetetrahydrofolate reductase gene polymorphism and plasma homocysteine levels in type 2 diabetes mellitus patients with diabetic retinopathy. Zhonghua Yi Xue Yi Chuan Xue Za Zhi 2003 20:131-134

37. Movva S, Alluri RV, Venkatasubramanian S, Vedicherla B, Vattam KK, et al: Association of methylene tetrahydrofolate reductase C677T genotype with type 2 diabetes mellitus patients with and without renal complications. Genet Test Mol Biomarkers 2011, 15:257-261.
38. Bazzaz JT, Shojapoor M, Nazem H, Amiri P, Fakhrzadeh $H$, et al: Methylenetetrahydrofolate reductase gene polymorphism in diabetes and obesity. Mol Biol Rep 2010, 37:105-109.

39. Benrahma H, Abidi O, Melouk L, Ajjemami M, Rouba H, et al: Association of the C677T Polymorphism in the Human Methylenetetrahydrofolate Reductase (MTHFR) gene with the genetic predisposition for Type 2 diabetes mellitus in a Moroccan Population. Genet Test Mol Biomarkers 2012, 16:383-387.

40. Sharaf SM, Gawish HH, Elsherbiny EM: Methylenetetrahydrofolate Reductase (Mthfr C677t) Gene Polymorphism Effect on Development of Diabetic Nephropathy in Egyptien Patients with Type 2 Diabetes Mellitus. Life Science Journal-Acta Zhengzhou University Overseas Edition 2012, 9:874-880.

41. Higgins JP, Thompson SG: Quantifying heterogeneity in a meta-analysis. Stat Med 2002, 21:1539-1558.

42. Song YQ, Yeung E, Liu AY, VanderWeele TJ, Chen LW, et al: Pancreatic beta-cell function and type 2 diabetes risk: quantify the causal effect using a Mendelian randomization approach based on meta-analyses. Hum Mol Genet 2012, 21:5010-5018.

43. Glymour MM, Tchetgen EJT, Robins JM: Credible mendelian randomization studies: approaches for evaluating the instrumental variable assumptions. Am J Epidemiol 2012, 175:332-339.

44. Tanaka T, Scheet P, Giusti B, Bandinelli S, Piras MG, et al: Genome-wide association study of vitamin B6, vitamin B12, folate, and homocysteine blood concentrations. Am J Hum Genet 2009, 84:477-482.

45. Huang T, Tucker KL, Lee YC, Crott JW, Parnell LD, et al: Methylenetetrahydrofolate reductase variants associated with hypertension and cardiovascular disease interact with dietary polyunsaturated fatty acids to modulate plasma homocysteine in puerto rican adults. J Nutr 2011, 141:654-659.

46. Thompson JR, Minelli C, Abrams KR, Tobin MD, Riley RD: Meta-analysis of genetic studies using Mendelian randomization - a multivariate approach. Stat Med 2005, 24:2241-2254

47. Wald DS, Law M, Morris JK: Homocysteine and cardiovascular disease: evidence on causality from a meta-analysis. Br Med J 2002, 325:1202-1206K.

48. Mazza A, Motti C, Nulli A, Pastore A, Andreotti F, et al: Serum homocysteine, MTHFR gene polymorphism, and carotid intimal-medial thickness in NIDDM subjects. J Thromb Thrombolysis 1999, 8:207-212.

49. Hermans MP, Gala JL, Buysschaert M: The MTHFR C677T polymorphism confers a high risk for stroke in both homozygous and heterozygous $\mathrm{T}$ allele carriers with Type 2 diabetes. Diabet Med 2006, 23:529-536.

50. Scaglione L, Gambino R, Rolfo E, Lillaz E, Gai M, et al: Plasma homocysteine, methylenetetrahydrofolate reductase gene polymorphism and carotid intima-media thickness in Italian type 2 diabetic patients. Eur J Clin Invest 2002, 32:24-28.

51. Ozmen B, Ozmen D, Turgan N, Habif S, Mutaf I, et al: Association between homocysteinemia and renal function in patients with type 2 diabetes mellitus. Ann Clin Lab Sci 2002, 32:279-286.

52. Tessari $\mathrm{P}$, Coracina A, Kiwanuka E, Vedovato M, Vettore M, et al: Effects of insulin on methionine and homocysteine kinetics in type 2 diabetes with nephropathy. Diabetes 2005, 54:2968-2976.

53. Helfenstein $T$, Fonseca FAH, Relvas WGM, Santos AO, Dabela ML, et al: Prevalence of myocardial infarction is related to hyperhomocysteinemia but not influenced by C677T methylenetetrahydrofolate reductase and A2756G methionine synthase polymorphisms in diabetic and nondiabetic subjects. Clin Chim Acta 2005, 355:165-172.

54. Koubaa N, Nakbi A, Smaoui A, Abid N, Chaaba R, et al: yperhomocysteinemia and elevated ox-LDL in Tunisian type 2 diabetic patients: role of genetic and dietary factors. Clin Biochem 2007, 40:1007-1014.

55. Ratnam S, Maclean KN, Jacobs RL, Brosnan ME, Kraus JP, et al: Hormonal regulation of cystathionine beta-synthase expression in liver. J Biol Chem 2002, 277:42912-42918.

56. Dicker-Brown A, Fonseca VA, Fink LA, Kern PA: The effect of glucose and insulin on the activity of methylene tetrahydrofolate reductase and cystathionine-beta-synthase: studies in hepatocytes. Atherosclerosis 2001 158:297-301.

57. Kluijtmans LA, van den Heuvel LP, Boers GH, Frosst P, Stevens EM, et al: Molecular genetic analysis in mild hyperhomocysteinemia: a common mutation in the methylenetetrahydrofolate reductase gene is a genetic risk factor for cardiovascular disease. Am J Hum Genet 1996, 58:35-41. 
58. Moczulski D, Fojcik H, Zukowska-Szczechowska E, Szydlowska I, Grzeszczak W: Effects of the C677T and A1298C polymorphisms of the MTHFR gene on the genetic predisposition for diabetic nephropathy. Nephrol Dial Transplant 2003, 18:1535-1540.

59. Chango A, Potier De Courcy G, Boisson F, Guilland JC, Barbe F, et al: 5,10methylenetetrahydrofolate reductase common mutations, folate status and plasma homocysteine in healthy French adults of the Supplementation en Vitamines et Mineraux Antioxydants (SU.VI.MAX) cohort. Br J Nutr 2000, 84:891-896.

60. Kluijtmans LA, Young IS, Boreham CA, Murray L, McMaster D, et al: Genetic and nutritional factors contributing to hyperhomocysteinemia in young adults. Blood 2003, 101:2483-2488.

61. Brown KS, Kluijtmans LA, Young IS, Murray L, McMaster D, et al: The 5,10methylenetetrahydrofolate reductase C677T polymorphism interacts with smoking to increase homocysteine. Atherosclerosis 2004, 174:315-322.

62. Maeda M, Yamamoto I, Fukuda M, Nishida M, Fujitsu J, et al: MTHFR gene polymorphism as a risk factor for diabetic retinopathy in type 2 diabetic patients without serum creatinine elevation. Diabetes Care 2003, 26:547-548.

63. Ksiazek P, Bednarek-Skublewska A, Buraczynska M: The C677T methylenetetrahydrofolate reductase gene mutation and nephropathy in type 2 diabetes mellitus. Med Sci Monit 2004, 10:BR47-51.

64. Ioannidis JPA, Ntzani EE, Trikalinos TA: 'Racial' differences in genetic effects for complex diseases. Nat Genet 2004, 36:1312-1318.

65. Ioannidis JPA, Trikalinos TA, Ntzani EE, Contopoulos-loannidis DG: Genetic associations in large versus small studies: an empirical assessment. Lancet 2003, 361:567-571.

66. Pfeiffer CM, Huff DL, Smith SJ, Miller DT, Gunter EW: Comparison of plasma total homocysteine measurements in 14 laboratories: an international study. Clin Chem 1999, 45:1261-1268.

67. Song Y, Cook NR, Albert CM, Van Denburgh M, Manson JE: Effect of homocysteine-lowering treatment with folic Acid and B vitamins on risk of type 2 diabetes in women: a randomized, controlled trial. Diabetes 2009, 58(8):1921-8.

doi:10.1186/1471-2164-14-867

Cite this article as: Huang et al: Association of homocysteine with type 2 diabetes: a meta-analysis implementing Mendelian randomization approach. BMC Genomics 2013 14:867.

\section{Submit your next manuscript to BioMed Central and take full advantage of:}

- Convenient online submission

- Thorough peer review

- No space constraints or color figure charges

- Immediate publication on acceptance

- Inclusion in PubMed, CAS, Scopus and Google Scholar

- Research which is freely available for redistribution 